\title{
Improvement in Quality of Life and Hemodynamics in Chronic Thromboembolic Pulmonary Hypertension Treated With Balloon Pulmonary Angioplasty
}

\author{
Szymon Darocha, MD; Radosław Pietura, MD, PhD; Arkadiusz Pietrasik, MD, PhD; \\ Justyna Norwa, MD; Anna Dobosiewicz, MD; Michał Piłka, MD; Michał Florczyk, MD; \\ Andrzej Biederman, MD, PhD; Adam Torbicki, MD, PhD; Marcin Kurzyna, MD, PhD
}

Background: The effect of balloon pulmonary angioplasty (BPA) on improvement in functional and hemodynamic parameters in chronic thromboembolic pulmonary hypertension (CTEPH) is known, but the quality of life (QoL) of patients treated with BPA has never been studied before.

Methods and Results: Twenty-five patients with inoperable or persistent CTEPH were enrolled in the study and filled out the 36 -item Short Form (SF-36v2) questionnaire twice: prior to commencement of BPA treatment and after $\geq 3$ BPA sessions. In addition WHO functional class, distance on the 6-min walk test (6MWT) and hemodynamic parameters such as right atrial pressure (RAP), mean pulmonary artery pressure (mPAP), cardiac index $(\mathrm{Cl})$ and pulmonary vascular resistance (PVR) were assessed. QoL improved significantly in all domains, except for physical pain. Improvement in RAP (10.5 \pm 3.4 vs. $6.2 \pm 2.2 \mathrm{mmHg}$; $\mathrm{P}<0.05)$, mPAP $(51.7 \pm 10.6$ vs. $35.0 \pm 9.1 \mathrm{mmHg} ; \mathrm{P}<0.05), \mathrm{Cl}\left(2.2 \pm 0.5\right.$ vs. $\left.2.5 \pm 0.4 \mathrm{~L} / \mathrm{min} \cdot \mathrm{m}^{2} ; \mathrm{P}=0.04\right)$, PVR (10.4 \pm 3.9 vs. $5.5 \pm 2.2$ Wood units; $\left.P<0.05\right)$, functional class $(96 \%$ vs. $20 \%$ in WHO class III and IV, $\mathrm{P}<0.05)$ and improvement in 6 MWT distance $(323 \pm 135$ vs. $410 \pm 109 \mathrm{~m}$; $P<0.05)$ was observed. The only significant correlation was between the mental component summary score of QoL after completion of treatment and percentage improvement in the 6MWT $(-0.404, \mathrm{P}<0.05)$.

Conclusions: Alongside improvement in functional and hemodynamic parameters, BPA also provides significant improvement in QoL.

Key Words: Balloon pulmonary angioplasty; Chronic thromboembolic pulmonary hypertension; Quality of life

C hronic thromboembolic pulmonary hypertension $(\mathrm{CTEPH})$ is a rare but dangerous disease caused by the presence of chronic thrombi in pulmonary arteries. The gold standard in the treatment of CTEPH is a surgical procedure: pulmonary endarterectomy (PEA), which significantly improves the prognosis in this group of patients. ${ }^{1,2}$ Additionally, after successful PEA significant reduction of symptoms as well as improvement in walk test distance, hemodynamic parameters, quality of life (QoL) and exercise capacity have been observed. ${ }^{3-7}$ Unfortunately, despite constant improvements in surgical technique, approximately $50 \%$ of patients with CTEPH do not qualify for surgical treatment, mainly due to a peripheral location of thrombi in the pulmonary bed. In approximately $16-30 \%$ of operated patients, PH persists despite PEA. ${ }^{8}$

\begin{abstract}
Editorial p442
Balloon pulmonary angioplasty (BPA) is a novel method of treating inoperable or persistent CTEPH. It has been shown to improve hemodynamic, echocardiographic, biochemical and functional parameters in patients with inoperable CTEPH, ${ }^{9-17}$ but the effect of BPA on QoL has never been studied.
\end{abstract}

\section{Methods}

\section{Subjects}

All patients included in the study had a diagnosis of CTEPH established on the basis of typical post-embolic changes in

Received October 24, 2016; revised manuscript received December 2, 2016; accepted December 27, 2016; released online February 1, 2017 Time for primary review: 28 days

Department of Pulmonary Circulation and Thromboembolic Diseases, European Health Centre Otwock, Medical Centre for Postgraduate Education, Otwock (S.D., J.N., A.D., M.P., M.F., A.T., M.K.); Department of Radiography, Medical University of Lublin, Lublin (R.P.); Department and Faculty of Cardiology, Medical University of Warsaw, Warsaw (A.P.); and Department of Cardiac Surgery, Medicover Hospital, Warsaw (A.B.), Poland

Mailing address: Marcin Kurzyna, MD, PhD, Department of Pulmonary Circulation and Thromboembolic Diseases, Medical Centre for Postgraduate Education, European Health Centre Otwock, Borowa 14/18, 05-400 Otwock, Poland. E-mail: marcin. kurzyna@ecz-otwock.pl

ISSN-1346-9843 All rights are reserved to the Japanese Circulation Society. For permissions, please e-mail: cj@j-circ.or.jp 


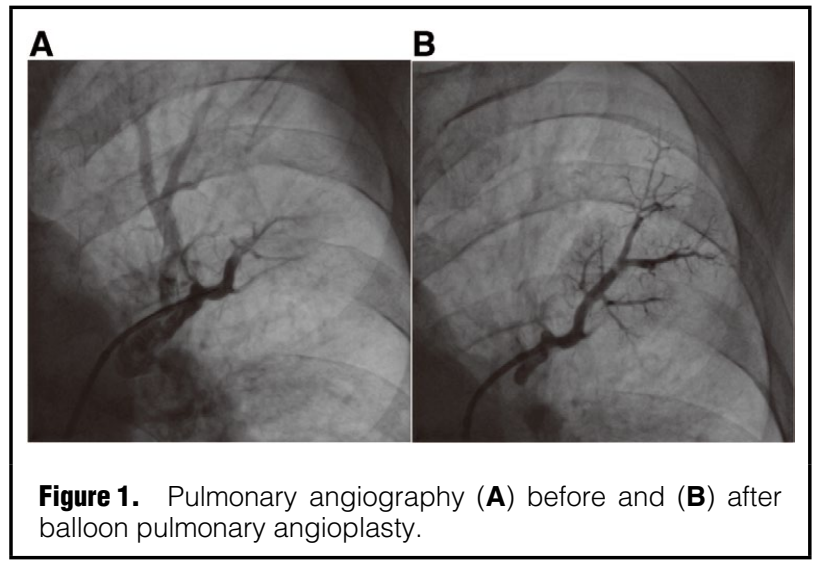

pulmonary arteries on diagnostic imaging (computed tomography angiography or perfusion lung scintigraphy, classic lung angiography) and signs of precapillary $\mathrm{PH}$ identified during right heart catheterization (RHC) persisting despite at least 3 months of anti-thrombotic therapy. The choice of treatment was assessed by a multidisciplinary CTEPH-team consisting of a cardiac surgeon with experience in PEA (A.B.), an interventional cardiologist with experience in BPA (M.K.) and a cardiologist experienced in using specific treatment (A.T.) for pulmonary arterial hypertension (PAH). Qualification for BPA required consensus of the 3 specialists.

All patients included in the study underwent non-invasive and invasive examinations prior to BPA. The same examinations were repeated 3-6 months after the last BPA session.

\section{RHC}

A Swan-Ganz catheter was used to measure right atrial pressure (RAP), pulmonary artery pressure (PAP) and pulmonary capillary wedge pressure (PCWP). Cardiac output (CO) was measured using thermodilution technique. Pulmonary vascular resistance (PVR) and cardiac index (CI) were calculated according to the accepted standards. In each patient, mean PAP (mPAP) $>25 \mathrm{mmHg}$ and PCWP $\leq 15 \mathrm{mmHg}$ was confirmed. ${ }^{18}$

\section{QoL and Exercise Capacity}

For the purposes of this study, a license number QM036623 was obtained for using the 36-item Short Form (SF-36v2) QoL questionnaire. Prior to BPA and after completion, each patient was asked to fill out the SF-36v2 questionnaire, Polish language version. At the same time the physician attending a given patient evaluated exercise capacity according to the score developed by the World Health Organization (WHO). The data obtained from the SF-36v2 questionnaires were collected and analyzed using Certified Scoring Software 5.0 $0^{\mathrm{TM}}$ (OPTUM, Eden Prairie, MN, USA). QoL was evaluated on 8 scales: physical functioning (PF), role-physical (RP), bodily pain (BP), general health $(\mathrm{GH})$, vitality (VT), social functioning (SF), role-emotional (RE) and mental health $(\mathrm{MH})$. The appropriate scales combined into groups summarize 4 parameters for evaluating the physical sphere (physical component summary, PCS) and 4 parameters for evaluating the mental sphere (mental component summary, $\mathrm{MCS}$ ): $\mathrm{PCS}=\mathrm{PF}+\mathrm{RF}+\mathrm{BT}+\mathrm{GH}$; and $\mathrm{MCS}=\mathrm{VT}+\mathrm{SF}+\mathrm{RE}+\mathrm{MH}$.

\begin{tabular}{|lc|}
\hline \multicolumn{2}{|c|}{ Table 1. Baseline Subject Characteristics } \\
Patients & BPA population \\
Female & 25 \\
Age (years) & 12 \\
WHO FC & $58.5 \pm 18.2$ \\
I & \\
II & 0 \\
III & 1 \\
IV & 20 \\
Use of specific pulmonary vasodilators & 4 \\
Monotherapy & $19(76)$ \\
PDE5i & \\
ERA & $16(85)$ \\
sGCs & 0 \\
PGI2 & $1(5)$ \\
Combined therapy & 0 \\
PDE5i+PGI2 & \\
\hline
\end{tabular}

Data given as $\mathrm{n}(\%)$ or mean \pm SD. BPA, balloon pulmonary angioplasty; ERA, endothelin receptor antagonist; PDE5i, phosphodiesterase type 5 inhibitor; PGI2, prostaglandin I2 (prostacyclin) analog; sGCs, synthetic guanylate cyclase stimulator; WHO FC, World Health Organization functional class.

For a normalized score of 1-100, the mean established in each domain was 50 points with an SD of 10 points. This standard has been established on the basis of a study of the healthy American population that was carried out in 1998. All patients underwent 6-min walk test (6MWT) prior to initiation of BPA treatment and after at least 3 BPA sessions.

\section{BPA}

The BPA was performed by 2 interventional cardiologists (M.K., A.P.) and an interventional radiologist (R.P.) experienced in coronary intervention, $\mathrm{RHC}$ and procedures on peripheral vessels. All patients undergoing BPA received a consent form and patient information sheet regarding the nature of the procedure and possible complications. The study protocol was approved by the Bioethics Committee at the Medical Center of Postgraduate Education.

The BPA was normally carried out using access through the right femoral vein, with unfractionated heparin given at a dose of $1-2,000 \mathrm{units} / \mathrm{h}$. Chronic anti-thrombotic treatment with vitamin $\mathrm{K}$ antagonists (VKA) or new oral anticoagulants (NOAC) was discontinued at least $24 \mathrm{~h}$ before the procedure. During the procedure, patients on long-term oxygen treatment, received it at the same constant flow rate. An MPA, JR 4 or AL1 6-F guiding catheter (Launcher; Meditronic, Minneapolis, MN, USA) was inserted into the right or left pulmonary artery using a 90-cm 6-F vascular sheath (Flexor; Cook, Bloomington, IN, USA). In the initial phase of the study, peripheral guidewires (V-14 and V-18 Controlwire; Boston Scientific, Natick, MA, USA) were used, which were later replaced with 0.014-in guidewires (Cruiser; Biotronik, Bülach, Switzerland; Whisper MS; Abbott Vascular, Santa Clara, CA, USA). Semicompliant balloon catheters with a size between $1.25 \mathrm{~mm}$ and $10 \mathrm{~mm}$ (Pantera, Biotronik; Passeo, Biotronik) were used. The balloon width and length was adjusted to the type of the lesion and degree of stenosis of the pulmonary artery on angiography. After inflation, 


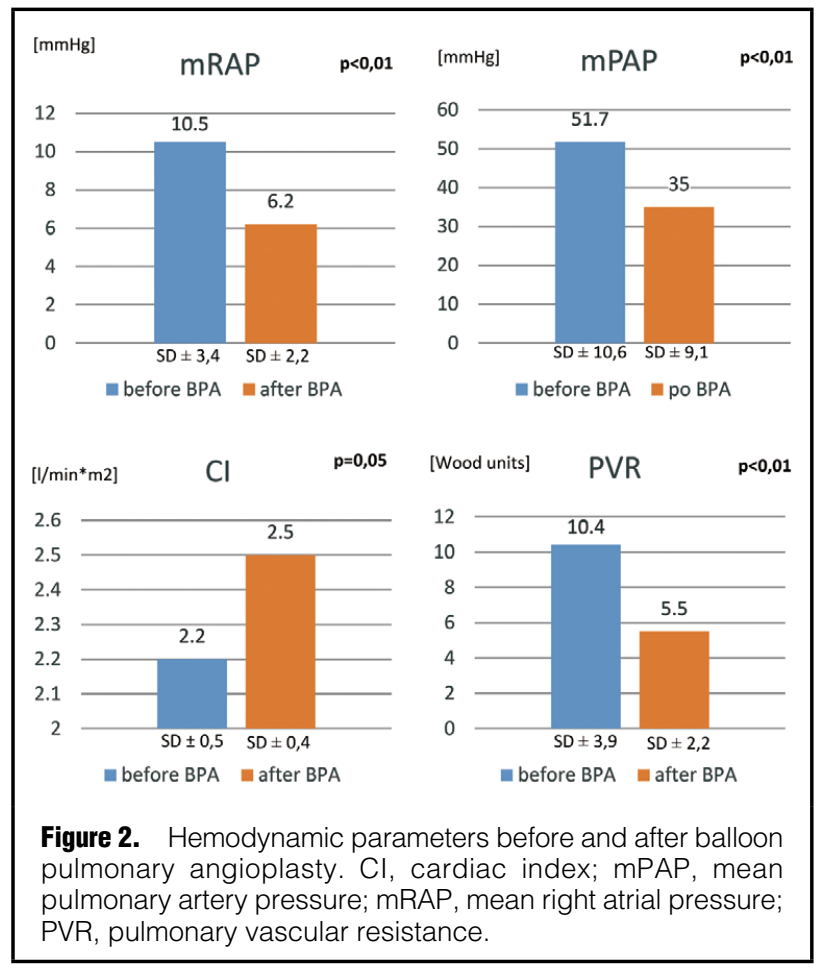

contrast agent was injected into the treated vessel in order to evaluate the angiographic effect of the procedure: analysis of flow across the treated lesion, peripheral parenchymal perfusion and venous return from the revascularized segment (Figure 1). Final angiography was also carried out in order to rule out possible injury to the vessel. In special cases in which there were doubts about the nature or significance of a lesion, additional diagnostic tools were used such as intravascular ultrasound or evaluation of the pressure gradient across the evaluated lesion using a pressure wire. After completion of the procedure, each patient was transferred to the cardiac intensive care unit in order to monitor vital functions and potential complications within $48 \mathrm{~h}$.

\section{Statistical Analysis}

Categorical variables are presented as count (percentage), and continuous variables as mean \pm SD. Student's t-test was used for comparison of data before and after BPA for continuous variables, and chi-squared test for categorical variables. Spearman correlation was used to test for association between QoL indices and change in hemodynamic variables after BPA. $\mathrm{P}<0.05$ was considered statistically significant. All statistical analysis was performed using STATISTICA 10 (STATSOFT, Tulsa, OK, USA).

\section{Results}

Twenty-five patients with CTEPH hospitalized in the Department of Pulmonary Circulation and Thromboembolic Diseases of the European Health Center, Poland were included in the study (Table 1). In this group, 22 patients $(88 \%)$ had inoperable CTEPH, mainly due to a distal location of thrombi $(n=18 ; 72 \%)$, or contraindications for surgery due to comorbidities and a high periprocedural risk $(n=4$;

\begin{tabular}{|c|c|c|}
\hline & $\begin{array}{c}\text { Baseline } \\
(n=25)\end{array}$ & $\begin{array}{l}\text { Follow-up } \\
(\mathrm{n}=25)\end{array}$ \\
\hline \multicolumn{3}{|c|}{ General health condition } \\
\hline Excellent & 0 & $1(4)$ \\
\hline Very good & 0 & $2(8)$ \\
\hline Good & $1(4)$ & $11(44)$ \\
\hline Fair & $8(32)$ & $9(36)$ \\
\hline Poor & $16(64)$ & $2(8)$ \\
\hline \multicolumn{3}{|c|}{ Compared with 1 year previously } \\
\hline Much better & $1(4)$ & $20(80)$ \\
\hline Somewhat better & $3(12)$ & $4(16)$ \\
\hline About the same & $3(12)$ & 0 \\
\hline Somewhat worse & $11(44)$ & $1(4)$ \\
\hline Much worse & $7(28)$ & 0 \\
\hline
\end{tabular}

Data given as $\mathrm{n}(\%)$. BPA, balloon pulmonary angioplasty; SF-36v2, 36-item Short Form.

$16 \%$ ). Additionally 3 patients (12\%) were diagnosed with persistent PH despite previous PEA, and BPA was carried out as a complementary treatment. All patients underwent at least 3 BPA sessions or completed BPA treatment due to satisfactory clinical effect.

In the study group, 96 BPA sessions (mean, 3.8 \pm 1.3 per patient) were carried out. In total, 447 pulmonary vessels (mean, 17.8 \pm 11.5 per patient) were treated. The most frequent complication observed during BPA was desaturation, which usually resolved within $24-48 \mathrm{~h}$ of oxygen therapy. Mild hemoptysis $(<50 \mathrm{~mL} / 24 \mathrm{~h})$ was observed during 5 BPA sessions $(5.2 \%)$. None of the patients required noninvasive positive pressure ventilation. Intubation was not necessary. In 4 cases $(4.1 \%)$ the pulmonary artery was injured by the guidewire, in 2 cases emergency balloon inflation in the injured vessel was performed, and 1 injured vessel underwent embolization.

Compared with baseline, MPAP and mean RAP were significantly reduced after a series of BPA, from $51.7 \pm 10.6$ to $35.0 \pm 9.1 \mathrm{mmHg} \quad(\mathrm{P}<0.01)$ and from $10.5 \pm 3.4$ to $6.2 \pm 2.2 \mathrm{mmHg}(\mathrm{P}<0.01)$, respectively. An increase in CI (from $2.2 \pm 0.5$ to $2.5 \pm 0.4 \mathrm{~L} / \mathrm{min} \cdot \mathrm{m}^{2}, \mathrm{P}<0.05$ ) was observed, and PVR decreased on average by $47 \%$ : from $10.4 \pm 3.9$ to $5.5 \pm 2.2$ Wood units $(\mathrm{P}<0.01)$. PCWP remained unchanged. Figure 2 presents the baseline and follow-up hemodynamics. A significant increase in $6 \mathrm{MWT}$ distance $(323 \pm 135$ vs. $410 \pm 109 \mathrm{~m}$; $\mathrm{P}<0.001)$ was also observed. Prior to BPA, $96 \%$ of patients had symptoms of WHO functional class III and IV. The percentage of patients in class III and IV decreased to $20 \%$ after at least $3 \mathrm{BPA}$ sessions $(\mathrm{P}<0.05)$.

At baseline evaluation using the SF-36v2 questionnaire, $64 \%$ of respondents described their general health status as unsatisfactory, and 44\% stated that they felt somewhat worse than 1 year ago. After completing BPA treatment, $44 \%$ of patients described their general health status as good, and $80 \%$ felt a significant improvement compared with the previous year $(\mathrm{P}<0.05$; Table 2$)$.

Baseline QoL in the CTEPH patients was significantly worse compared with the healthy population. After a series of BPA, a significant improvement was observed in QoL on all the scales and on scales normalized relative to the healthy population, except for pain experience (Table 3). Both PCS and MCS spheres underwent significant 


\begin{tabular}{|c|c|c|c|c|c|c|}
\hline & \multicolumn{3}{|c|}{ Scale scores } & \multicolumn{3}{|c|}{ Normalized scale scores } \\
\hline & Before BPA & After BPA & $P$ value & Before BPA & After BPA & $P$ value \\
\hline PF & 29 & 62.4 & 0.001 & 26.9 & 41.3 & 0.001 \\
\hline $\mathrm{RP}$ & 9 & 57 & 0.001 & 29.6 & 44 & 0.001 \\
\hline BP & 57.3 & 66.3 & 0.185 & 44.6 & 48.3 & 0.186 \\
\hline $\mathrm{GH}$ & 30.6 & 46.1 & 0.001 & 31.3 & 38.7 & 0.001 \\
\hline VT & 35 & 62.4 & 0.001 & 39.2 & 52.5 & 0.001 \\
\hline SF & 52 & 77 & 0.001 & 35.8 & 47.1 & 0.001 \\
\hline RE & 33.3 & 74.6 & 0.001 & 35 & 47.3 & 0.008 \\
\hline $\mathrm{MH}$ & 55.6 & 73.9 & 0.001 & 39.2 & 49.3 & 0.001 \\
\hline PCS & 29.5 & 39.4 & 0.001 & - & - & - \\
\hline MCS & 41 & 51.9 & 0.024 & - & - & - \\
\hline
\end{tabular}

BP, bodily pain; GH, general health; MCS, mental component summary; MH, mental health; PCS, physical component summary; PF, physical functioning; RE, role-emotional; RP, role-physical; SF, social functioning; VT, vitality. Other abbreviations as in Table 2.

improvement after a series of BPA (Table 3). Transformation of the scores into a $0-100$ scale and comparison with the healthy population are presented in Figures 3,4. No significant correlation between the number of pulmonary vessels treated and improvement in MCS $(\mathrm{r}=-0.083 ; \mathrm{P}=0.703)$ and in PCS $(\mathrm{r}=-0.113 ; \mathrm{P}=0.589)$ was found. Also, no significant correlation between the number of BPA sessions and improvement in MCS $(\mathrm{r}=0.098 ; \mathrm{P}=0.641)$ or in PCS $(\mathrm{r}=-0.185 ; \mathrm{P}=0.376)$ was seen. Reduction in PVR after a series of BPA did not correlate with improvement in PCS $(r=-0.004 ; P=0.984)$ or in MCS $(r=0.116, P=0.58)$. Similarly, decrease in mPAP after a series of BPA did not correlate with improvement in MCS $(\mathrm{r}=0.285 ; \mathrm{P}=0.166)$ or in PCS $(\mathrm{r}=0.164 ; \mathrm{P}=0.434)$. Improvement in $\mathrm{CO}$ did not correlate with improvement in MCS $(\mathrm{r}=0.047 ; \mathrm{P}=0.822)$ or in PCS $(\mathrm{r}=0.011 ; \mathrm{P}=0.956)$. Functional improvement observed on 6MWT correlated only with MCS $(\mathrm{r}=-0.404 ; \mathrm{P}<0.05)$ evaluated after treatment completion. Correlations between particular QoL domains evaluated after treatment completion and the number of procedures, number of vessels with restored patency, reduction in mPAP, improvement in $\mathrm{CO}$, reduction in PVR and improvement in the 6MWT are listed in Table 4.

\section{Discussion}

Balloon angioplasty seems to be a very promising method of treating inoperable CTEPH and persistent CTEPH despite surgical treatment. Its beneficial effect on hemodynamic, biochemical, echocardiographic and functional parameters has been convincingly demonstrated., ${ }^{912,13,19-22}$ The hemodynamic and functional efficacy of BPA was also confirmed in the present study. The main goal, however, was to investigate whether BPA may also influence QoL in CTEPH. The evaluation of QoL in CTEPH patients may be a very useful tool, facilitating analysis of everyday physical functioning, determination of limitations in the performance of roles, definition of general health and vitality, and evaluation of mental health quality.

Currently, there are many QoL questionnaires developed and available for use, but there is no such questionnaire designed specifically for CTEPH patients. From among various tools used to evaluate QoL, the SF-36v2 questionnaire was chosen due to its widespread use, including in the evaluation of QoL in PH., 4,23,24
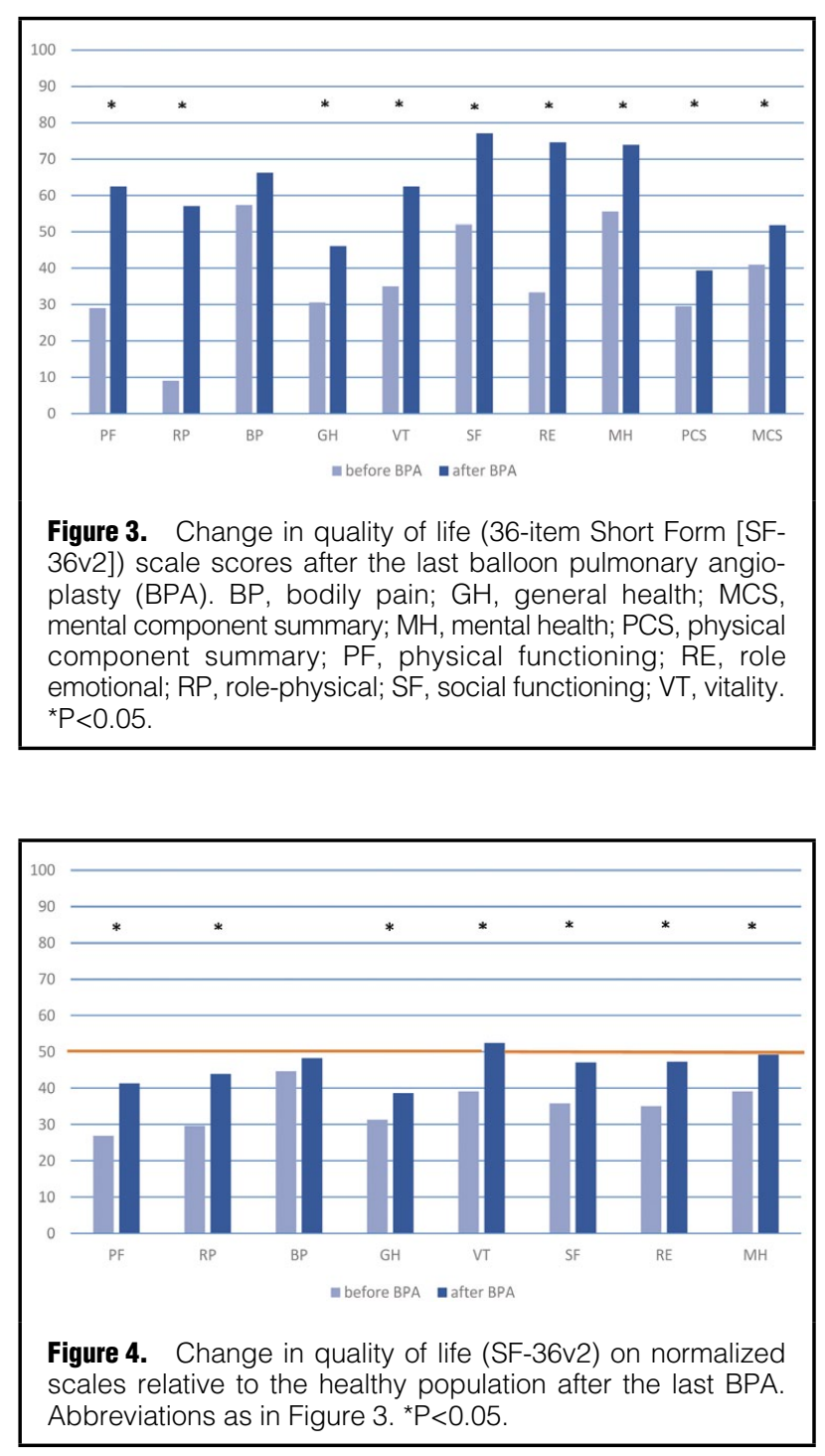

The SF-36v2 was used for a group of 62 Finnish patients with various forms of $\mathrm{PH}$ who received pharmacological therapy specific for PAH. In that group, 21 patients had 


\begin{tabular}{|c|c|c|c|c|c|c|}
\hline $\begin{array}{l}\text { SF-36 scores at } \\
\text { follow-up }\end{array}$ & $\begin{array}{l}\text { No. arteries } \\
\text { ( } \mathrm{r} \text { value) }\end{array}$ & $\begin{array}{l}\text { No. sessions } \\
\text { ( } r \text { value) }\end{array}$ & $\begin{array}{c}\text { mPAP \% change } \\
\text { ( } r \text { value) }\end{array}$ & $\begin{array}{c}\mathrm{Cl} \% \text { change } \\
\text { ( } \mathrm{r} \text { value) }\end{array}$ & $\begin{array}{l}\text { PVR \% change } \\
\text { ( } r \text { value) }\end{array}$ & $\begin{array}{c}\text { 6MWT \% change } \\
\text { ( } r \text { value) }\end{array}$ \\
\hline PF & -0.036 & -0.176 & 0.312 & -0.164 & 0.127 & -0.221 \\
\hline $\mathrm{RP}$ & 0.030 & -0.031 & 0.175 & 0.064 & 0.101 & -0.120 \\
\hline BP & 0.155 & -0.044 & -0.039 & 0.064 & -0.178 & 0.071 \\
\hline GH & -0.033 & -0.104 & -0.012 & -0.155 & 0.010 & -0.297 \\
\hline VT & -0.011 & 0.134 & 0.047 & -0.123 & 0.093 & -0.117 \\
\hline SF & 0.066 & 0.160 & -0.171 & -0.093 & -0.040 & -0.263 \\
\hline $\mathrm{RE}$ & 0.210 & 0.206 & 0.021 & 0.030 & -0.043 & -0.379 \\
\hline $\mathrm{MH}$ & -0.011 & 0.172 & -0.101 & -0.006 & -0.054 & -0.336 \\
\hline PCS & -0.001 & -0.221 & 0.096 & 0.040 & 0.069 & -0.005 \\
\hline MCS & 0.011 & 0.320 & -0.103 & -0.045 & 0.007 & $-0.404^{*}$ \\
\hline
\end{tabular}

${ }^{*} \mathrm{P}<0.05$. QoL, quality of life. Other abbreviations as in Tables 2,3.

inoperable CTEPH. All subjects had a significantly lower QoL, except for the MH domain and the mental sphere (MCS), compared with the general population. ${ }^{25}$ Decreased QoL was also found in the present cohort of $25 \mathrm{CTEPH}$ patients prior to the first BPA session.

The effect on QOL in CTEPH has so far been evaluated only for 2 treatment methods, that is, PEA and pharmacological therapy with specific drugs targeted to small pulmonary arteries. The SF-36 questionnaire was used in 308 patients with CTEPH who underwent pulmonary endarterectomy. Significant improvement after surgical treatment was found within all QoL domains, except for the emotional domain (RE) ${ }^{\mathbf{2 6}}$ In another analysis, QoL was evaluated using the SF-36 questionnaire in 83 patients with CTEPH who were treated surgically or pharmacologically. A significant improvement was seen in the domain of PF $(\mathrm{P}<0.01), \mathrm{RP}(\mathrm{P}<0.05)$, VT $(\mathrm{P}<0.05)$, SF $(\mathrm{P}<0.05)$ and the $\mathrm{MH}(\mathrm{P}<0.01)$ in the PEA group, despite persistence of PH in some cases. ${ }^{27}$ Inoperable patients treated medically had improvement in QoL only in 2 domains: $\mathrm{RP}(\mathrm{P}<0.05)$ and VT $(\mathrm{P}<0.05)$. In patients with significant hemodynamic improvement after PEA, resulting in a decrease in PVR $>50 \%$ compared with baseline, a significantly improved QoL was found within the domain of $\mathrm{PF}(\mathrm{P}<0.01), \mathrm{RP}$ $(\mathrm{P}<0.045), \mathrm{GH}(\mathrm{P}<0.019), \mathrm{SF}(\mathrm{P}<0.017), \mathrm{RE}(\mathrm{P}<0.01)$ and $\mathrm{MH}(\mathrm{P}<0.03)$. No improvement in $\mathrm{QoL}$ was found in patients with decrease in PVR after PEA $<50 \% .{ }^{27}$

In the present study the mean reduction in PVR was approximately $47 \%$ and there was no significant correlation between any QoL domain and decrease in PVR. This could have been due to the smaller range of changes of PVR observed compared with PEA. Indeed, many of the present patients still had moderate $\mathrm{PH}$ of approximately $35 \mathrm{mmHg}$ after 3 BPA sessions, and were scheduled for additional interventions. Even at that phase of treatment, however, BPA improved QoL in several domains. This improvement could be more noticeable with more sessions dedicated to individual patients and a greater number of treated vessels. It is possible that together with further improved hemodynamics (including PVR) and functional capacity, the correlations between the changes in those variables and improvement in QoL would become more evident.

In treated group we found correlations only between the sphere of mental functioning (MCS) and increase in 6MWT ( $\mathrm{r}=-0.404 ; \mathrm{P}<0.05 ;$ Table 4). Greater 6MWT distance and lower PVR were associated with better QoL in the domains of PF and PCS in a recent multivariate analysis of $128 \mathrm{CTEPH}$ patients treated with PEA or medical therapy. ${ }^{23}$ Changes in QoL was also assessed in the landmark BENEFiT study, which compared, in a randomized, double-blind trial, the effect of bosentan vs. placebo in 157 patients with inoperable CTEPH or persistent CTEPH after PEA. No significant change in QoL on SF-36 questionnaire was found in the bosentan group compared with the placebo group. ${ }^{28}$ The CAMPHOR questionnaire was used in a small group of 19 patients with inoperable CTEPH treated with sildenafil. A significant improvement was achieved within the domain described as activity, but no correlations were found between QoL and other study endpoints such as improvement in 6MWT, reduction in $\mathrm{N}$-terminal pro-B-type natriuretic peptide concentration or improvement in hemodynamic parameters and WHO functional class. ${ }^{29}$ The pivotal CHEST-1 and CHEST-2 studies used the EuroQol-5D and Living with Pulmonary Hypertension Questionairre. Treatment with riociguat improved QoL in patients with inoperable CTEPH or persistent CTEPH after surgery. ${ }^{30,31}$

The present study is the first to show improvement in QoL on SF-36v2 in patients with CTEPH treated nonsurgically. The SF36v2, however, is not a perfect tool for evaluating QoL in CTEPH patients. This questionnaire refers to symptoms experienced during the last 4 weeks, and treatment with BPA is a long-term one that requires multiple sessions to be carried out with intervals of a few weeks or even months. Therefore, there is a possibility of this evaluation being distorted by fluctuations of the patient's psyche, irrespective of the clinical effect of BPA, which is usually beneficial. The evaluation of QoL may depend to a significant extent on the patient's current mood (depression or enthusiasm associated with hope for further improvement or its lack), which is a factor that is difficult to eliminate, but is easy to manipulate. In contrast to medical therapy, assessment of BPA cannot be made in a randomized blinded way. This makes comparison of the effects of those treatments on QoL difficult. Also, BPA and medical treatment are often used jointly, and in the present study $>80 \%$ of patients received targeted medical therapy before the initiation of BPA. ${ }^{32}$

In the present study, no correlation was found between improvement in QoL and the number of BPA sessions, number of vessels with restored patency and hemodynamic parameters, although the effect of BPA on these parameters was significant. The only significant correlation was between the sphere of mental functioning (MCS) after BPA and 
improvement in 6MWT distance. This shows that QoL may be an independent indicator of effectiveness of BPA.

Objectively evaluated improvement in QoL may be an additional aim of BPA treatment, especially in elderly patients and those with comorbidities associated with shortened life expectancy.

\section{Grants}

This study was carried out with support of funds from the statutory activity of the Medical Center for Postgraduate Education in Warsaw.

\section{References}

1. Konstantinides SV, Torbicki A, Agnelli G, Danchin N, Fitzmaurice D, Galie N, et al. 2014 ESC guidelines on the diagnosis and management of acute pulmonary embolism. Eur Heart J 2014; 35: 3033-3069, 3069a-3069k.

2. Kim NH, Delcroix M, Jenkins DP, Channick R, Dartevelle P, Jansa $\mathrm{P}$, et al. Chronic thromboembolic pulmonary hypertension. J Am Coll Cardiol 2013; 62: D92-D99.

3. Cenedese E, Speich R, Dorschner L, Ulrich S, Maggiorini M, Jenni R, et al. Measurement of quality of life in pulmonary hypertension and its significance. Eur Respir J 2006; 28: 808-815.

4. Halank M, Einsle F, Lehman S, Bremer H, Ewert R, Wilkens H, et al. Exercise capacity affects quality of life in patients with pulmonary hypertension. Lung 2013; 191: 337-343.

5. Mathai SC, Ghofrani HA, Mayer E, Pepke-Zaba J, Nikkho S, Simonneau G. Quality of life in patients with chronic thromboembolic pulmonary hypertension. Eur Respir J 2016; 48: 526537.

6. McCabe C, Bennett M, Doughty N, MacKenzie Ross R, Sharples L, Pepke-Zaba J. Patient-reported outcomes assessed by the CAMPHOR questionnaire predict clinical deterioration in idiopathic pulmonary arterial hypertension and chronic thromboembolic pulmonary hypertension. Chest 2013; 144: $522-$ 530 .

7. Roman A, Barbera JA, Castillo MJ, Munoz R, Escribano P. Health-related quality of life in a national cohort of patients with pulmonary arterial hypertension or chronic thromboembolic pulmonary hypertension. Arch Bronconeumol 2013; 49: 181-188.

8. Cannon JE, Su L, Kiely DG, Page K, Toshner M, Swietlik E, et al. Dynamic risk stratification of patient long-term outcome after pulmonary endarterectomy: Results From the United Kingdom National Cohort. Circulation 2016; 133: 1761-1771.

9. Inami T, Kataoka M, Shimura N, Ishiguro H, Yanagisawa R, Taguchi $\mathrm{H}$, et al. Pulmonary edema predictive scoring index (PEPSI), a new index to predict risk of reperfusion pulmonary edema and improvement of hemodynamics in percutaneous transluminal pulmonary angioplasty. JACC Cardiovasc Interv 2013; 6: 725-736.

10. Mizoguchi H, Ogawa A, Munemasa M, Mikouchi H, Ito H, Matsubara H. Refined balloon pulmonary angioplasty for inoperable patients with chronic thromboembolic pulmonary hypertension. Circ Cardiovasc Interv 2012; 5: 748-755.

11. Kataoka M, Inami T, Hayashida $\mathrm{K}$, Shimura $\mathrm{N}$, Ishiguro $\mathrm{H}$, Abe T, et al. Percutaneous transluminal pulmonary angioplasty for the treatment of chronic thromboembolic pulmonary hypertension. Circ Cardiovasc Interv 2012; 5: 756-762.

12. Sugimura K, Fukumoto Y, Satoh K, Nochioka K, Miura Y, Aoki T, et al. Percutaneous transluminal pulmonary angioplasty markedly improves pulmonary hemodynamics and long-term prognosis in patients with chronic thromboembolic pulmonary hypertension. Circ J 2012; 76: 485-488.

13. Fukui S, Ogo T, Morita Y, Tsuji A, Tateishi E, Ozaki K, et al. Right ventricular reverse remodelling after balloon pulmonary angioplasty. Eur Respir J 2014; 43: 1394-1402.

14. Shimura N, Kataoka M, Inami T, Yanagisawa R, Ishiguro H, Kawakami T, et al. Additional percutaneous transluminal pulmonary angioplasty for residual or recurrent pulmonary hypertension after pulmonary endarterectomy. Int J Cardiol 2015; 183: $138-142$.

15. Inami $\mathrm{T}$, Kataoka $\mathrm{M}$, Shimura $\mathrm{N}$, Ishiguro $\mathrm{H}$, Yanagisawa $\mathrm{R}$,
Fukuda K, et al. Pressure-wire-guided percutaneous transluminal pulmonary angioplasty: A breakthrough in catheter-interventional therapy for chronic thromboembolic pulmonary hypertension. JACC Cardiovasc Interv 2014; 7: 1297-1306.

16. Yanagisawa R, Kataoka M, Inami T, Shimura N, Ishiguro H, Fukuda K, et al. Safety and efficacy of percutaneous transluminal pulmonary angioplasty in elderly patients. Int J Cardiol 2014; 175: $285-289$

17. Ogawa A, Matsubara H. Balloon pulmonary angioplasty: A treatment option for inoperable patients with chronic thromboembolic pulmonary hypertension. Front Cardiovasc Med 2015; 2: 4.

18. Kurzyna M, Araszkiewicz A, Blaszczak P, Grabka M, Hawranek M, Kopec G, et al. Summary of recommendations for the haemodynamic and angiographic assessment of the pulmonary circulation: Joint statement of the Polish Cardiac Society's Working Group on Pulmonary Circulation and Association of Cardiovascular Interventions. Kardiol Pol 2015; 73: 63-68.

19. Feinstein JA, Goldhaber SZ, Lock JE, Ferndandes SM, Landzberg MJ. Balloon pulmonary angioplasty for treatment of chronic thromboembolic pulmonary hypertension. Circulation 2001; 103: 10-13.

20. Andreassen AK, Ragnarsson A, Gude E, Geiran O, Andersen R. Balloon pulmonary angioplasty in patients with inoperable chronic thromboembolic pulmonary hypertension. Heart 2013; 99: $1415-1420$

21. Darocha S, Kurzyna M, Pietura R, Torbicki A. Balloon pulmonary angioplasty for inoperable chronic thromboembolic pulmonary hypertension. Kardiol Pol 2013; 71: 1331

22. Kurzyna M, Darocha S, Koteja A, Pietura R, Torbicki A. Balloon pulmonary angioplasty for chronic thromboembolic pulmonary hypertension. Postepy Kardiol Interwencyjnej 2015; 11: 1-4.

23. Urushibara T, Tanabe N, Suda R, Kato F, Kasai H, Takeuchi $\mathrm{T}$, et al. Effects of surgical and medical treatment on quality of life for patients with chronic thromboembolic pulmonary hypertension. Circ J 2015; 79: 2696-2702.

24. Harzheim D, Klose H, Pinado FP, Ehlken N, Nagel C, Fischer $\mathrm{C}$, et al. Anxiety and depression disorders in patients with pulmonary arterial hypertension and chronic thromboembolic pulmonary hypertension. Respir Res 2013; 14: 104

25. Kukkonen M, Puhakka A, Halme M. Quality of life among pulmonary hypertension patients in Finland. Eur Clin Respir J 2016; 3: 26405.

26. Archibald CJ, Auger WR, Fedullo PF, Channick RN, Kerr KM, Jamieson SW, et al. Long-term outcome after pulmonary thromboendarterectomy. Am J Respir Crit Care Med 1999; 160: $523-$ 528.

27. Yoshimi S, Tanabe N, Masuda M, Sakao S, Uruma T, Shimizu $\mathrm{H}$, et al. Survival and quality of life for patients with peripheral type chronic thromboembolic pulmonary hypertension. Circ $J$ 2008; 72: $958-965$.

28. Jais X, D'Armini AM, Jansa P, Torbicki A, Delcroix M, Ghofrani HA, et al. Bosentan for treatment of inoperable chronic thromboembolic pulmonary hypertension: BENEFiT (Bosentan Effects in iNopErable Forms of chronIc Thromboembolic pulmonary hypertension), a randomized, placebo-controlled trial. J Am Coll Cardiol 2008; 52: 2127-2134.

29. Suntharalingam J, Treacy CM, Doughty NJ, Goldsmith K, Soon $\mathrm{E}$, Toshner MR, et al. Long-term use of sildenafil in inoperable chronic thromboembolic pulmonary hypertension. Chest 2008; 134: $229-236$.

30. Ghofrani HA, D'Armini AM, Grimminger F, Hoeper MM, Jansa P, Kim NH. Riociguat for the treatment of chronic thromboembolic pulmonary hypertension. $N$ Engl J Med 2013; 369: 319-329.

31. Simonneau G, D'Armini AM, Ghofrani HA, Grimminger F, Hoeper MM, Jansa P, et al. Riociguat for the treatment of chronic thromboembolic pulmonary hypertension: A long-term extension study (CHEST-2). Eur Respir J 2015; 45: 1293-1302.

32. Kawakami T, Ogawa A, Miyaji K, Mizoguchi H, Shimokawahara $\mathrm{H}$, Naito $\mathrm{T}$, et al. Novel angiographic classification of each vascular lesion in chronic thromboembolic pulmonary hypertension based on selective angiogram and results of balloon pulmonary angioplasty. Circ Cardiovasc Interv 2016; 9: pii:e003318. 